\title{
Dança: resgate e vivências na Educação Física escolar
}

\author{
Dance: rescue and experiences in Physical Education
}

\begin{abstract}
Livia Martinez Veras, ${ }^{1}$ Ana Cristina Tillmann, ${ }^{1}$ Nycolle Martins Reis, ${ }^{1}$ Adriana Coutinho de Azevedo Guimarães. ${ }^{2}$ 'Centro de Ciências da Saúde e do Esporte (CEFID). Universidade do Estado de Santa Catarina (UDESC), Florianópolis, SC, Brasil. 2Professora do Departamento de Educação Física e do Programa de Pós-Graduação em Ciências do Movimento Humano da Universidade do Estado de Santa Catarina (UDESC), Florianópolis, SC, Brasil.
\end{abstract}

Recebido em: abril 2015 / Aceito em: abril 2015

actillmann@gmail.com

\section{RESUMO}

Objetivo: analisar artigos referentes à dança no todo da Educação Física Escolar. Método: foram selecionados por meio de busca eletrônica, artigos publicados nos últimos 10 anos em revistas indexadas com qualis e/ou fator de impacto. Resultados: sete estudos atenderam aos critérios de inclusão, sendo quatro publicados na língua inglesa e os outros três na língua portuguesa. Destes, três tratavam da dança de salão na escola, um da dança de rua e os outros três do uso do videogame de dança na Educação Física escolar. Considerações finais: há uma lacuna na literatura, pois apenas três modalidades de dança foram associadas à Educação Física, sendo que outras podem ser exploradas neste contexto. A dança, assim como outras atividades utilizadas na Educação Física escolar, pode proporcionar benefícios ao estado biopsicossocial do aluno, desde as séries iniciais, necessitando ser mais explorada no ambiente escolar.

Palavras-chave: Escola; Atividade Motora; Criança.

\section{ABSTRACT}

Objective: this systematic review aimed to analyze dance related papers from physical education. Method: scientific papers published in the last 10 years in journals indexed with qualis and/or impact factor were selected by electronic search. Results: seven studies met the inclusion criteria, four published in English and three in Portuguese. Of these, three dealt with the ballroom dance at school, one with street dance and the other three use the dance videogame in physical education classes. Final considerations: we conclude that there is a gap in the literature, therefore only three dance forms were associated with physical education, and others can be explored in this context. The dance and other activities used in physical education can provide bene- fits to the biopsychosocial state of the student from the initial series, thus requiring a further exploration in the school setting.

Keywords: School; Motor Activity; Child.

\section{INTRODUÇÃO}

A dança é uma manifestação de grande valor em diversas culturas em todo o mundo e em variadas épocas da história'. Considerada uma forma de expressão corporal humana, modificou-se durante os períodos históricos, sendo inicialmente encontrada em rituais que demonstrassem a potencialidades físicas e expressão de sentimentos ${ }^{1-3}$. Sua importância se dá pela possibilidade de construção de conhecimentos e valores por meio do movimento ${ }^{1}$. Seu aprendizado acontece por meio de autoconhecimento do movimento, observando-se a cultura na qual se insere, a história construída pelo povo e consequentes manifestações expressivas ${ }^{4}$.

É no ambiente escolar, que as crianças e jovens interiorizam aprendizados necessários para a vida. Das danças eruditas às populares, todas proporcionam vivências válidas para os estudantes. Alguns pesquisadores $^{5-7}$ têm a visão de que é, a partir do processo criativo em dança, do desenvolvimento da criticidade e conhecimento da cultura de movimentos desenvolvidos pela dança na escola, que o indivíduo emancipa-se.

A dança é capaz de desenvolver indivíduos ética, cognitiva e esteticamente, auxiliando nas questões de socialização e expressão ${ }^{4}$. Esta tem o papel de ampliar a capacidade sensorial e de compreensão do mundo e, paralelamente, aumentar o repertório de comunicação do indivíduo ${ }^{1}$, bem como o ensino da boa postura, equilíbrio, coordenação e o ritmo fazendo com que as crianças aprendam a administrar e aproveitar os seus corpos de forma completa ${ }^{8}$. No contexto escolar, a dança entra como ferramenta facilitadora do aprendizado e foge da forma de ensino tradicional, na qual a técnica para formação 
de bailarinos é o elemento principal; aqui a dança surge como experiência expressiva, estimulando a criatividade e originalidade, por meio do movimento corporal ${ }^{9}$.

A Educação Física tem o papel de auxiliar na construção de conhecimentos e ser agente transformador dos jovens e crianças e da sociedade que o cerca ${ }^{10}$. Segundo os Parâmetros Curriculares Nacionais (PCN), o lugar da dança está garantido pela lei e suas diretrizes no sistema educacional nacional no ensino fundamental e médio ${ }^{11,12}$. O PCN do Ensino Médio (1999) destaca os benefícios que a Dança pode proporcionar aos jovens, por meio do desenvolvimento de sua expressividade, subsidiando uma melhor compreensão das relações entre a corporeidade, cultura corporal e a sociedade 13. Porém, apesar da evidente necessidade do conteúdo, ainda existem professores que resistem à aplicação desta, quer por descrença na profissão, por falta de compromisso ou ainda por falta de informação técnica ${ }^{14}$.

Fazendo uso do conhecimento descrito na literatura, sobre a dança e sua inserção na escola, o presente estudo justifica-se por proporcionar aos profissionais da área, um resgate das informações de forma sistematizada e atualizada sobre o que vem sendo trabalhado com relação à dança, trazendo consigo, além de sua importância na vida das crianças e jovens, inspiração e embasamento teórico para a realização de atividades deste cunho, na Educação Física Escolar. Sendo assim o objetivo deste estudo foi analisar artigos referentes à dança no todo da Educação Física Escolar, verificando quais os tipos de dança são mais comumente encontrados e de que forma são desenvolvidos neste contexto, publicados nos últimos dez anos.

\section{MÉTODO}

O presente estudo caracteriza-se como uma revisão sistemática de trabalhos científicos que estudaram a relação entre dança, escola e Educação Física. Foram selecionados, por meio de busca eletrônica, artigos das bases de dados, Medline, Pubmed, Science Direct, Lilacs (Literatura Latino-americana e do Caribe em Ciências da Saúde). Para uma maior abrangência de estudos nacionais, utilizou-se também a biblioteca virtual SciELO (Scientific Electronic Library Online). Publicados nos últimos dez anos (janeiro de 2004 ao dezembro de 2014) em revistas indexadas classificadas com Qualis A1 a B4 e/ ou fator de impacto, no ano da coleta de dados.

A estratégia de busca incluiu as palavras-chaves propostas nos descritores em ciências da saúde (DESCs): Dança, Escola, Educação Física, Atividade Física; Dance, School, Physical Education, Physical Activity; Danza, Escuela, Educación Física, la Actividad Física, presentes no título ou nos resumos dos artigos. Foram considerados critérios de inclusão os artigos em português, inglês e espanhol, envolvendo os descritores anteriormente citados, disponíveis em formato digital, além de uma busca secundária na lista bibliográfica dos artigos inicialmente avaliados, com objetivo de identificar outras importantes referências não captadas pela busca inicial, excluindo-se os estudos de Monografias, Teses, Dissertações e Revisões Sistemáticas. Após exclusão de artigos, que não cumpriram os critérios de inclusão juntamente com os artigos duplicados, foi realizado o fichamento de todos os artigos selecionados para organização da leitura.

Para maior confiabilidade do estudo, todo o processo de busca nas bases de dados eletrônicas, seleção dos estudos, leitura dos artigos e compilação das informações foi realizada pela pesquisadora principal deste estudo. Esse processo de busca e seleção foi replicado por um segundo pesquisador de maneira cega e independente, não sendo identificadas divergências quanto à seleção final dos artigos. Para análise dos dados e critérios de inclusão e exclusão, os artigos foram analisados de acordo com título e resumo. Os artigos foram lidos na íntegra para coleta das informações pertinentes à temática do estudo. Os estudos selecionados foram então catalogados de acordo com ano, periódico, qualis, fator de impacto, amostragem, métodos, instrumentos e resultados.

Com relação aos aspectos éticos, por se tratar de pesquisa bibliográfica com uso exclusivo de bases de dados públicos e, portanto, de não se tratar de pesquisa envolvendo seres humanos, essa pesquisa não foi submetida ao Comitê de Ética em Pesquisa.

\section{RESULTADOS}

A figura 1 apresenta o fluxograma da estratégia utilizada para a seleção dos artigos. Foram identificados 2.036 estudos; destes 2.017 foram excluídos, após aplicação da primeira etapa dos critérios de inclusão, resultando em 28 artigos para leitura integral, sendo 19 artigos da Scielo, um da Science Direct, três artigos da Medline e dois da Pubmed e três da Lilacs. Destes, 20 artigos foram excluídos por não se enquadrarem no tema do estudo, três por não se tratarem de artigo original. Desta forma, obtiveram-se cinco artigos a serem incluídos nos estudos. Por fim foram incluídos dois estudos por meio da pesquisa manual, resultando em sete artigos para análise nesta revisão.

Os sete artigos incluídos no estudo são apresentados no quadro 1 evidenciando ano, título, idioma, periódico, qualis do periódico, fator de impacto e base de dados em que foi encontrado. Dos artigos publicados, quatro foram publicados na língua inglesa e encontrados em periódicos com Fator de Impacto de 1.227 e 2.37, com predomínio na base de dados Science Direct. Dos artigos publicados na língua portuguesa, dois foram encontrados na base de dados Scielo e foram classificados com qualis " $A$ " e um com qualis " $B$ ". O outro publicado na língua portuguesa foi encontrado na base de dados Lilacs e está qualificado com Qualis "B".

Os achados mostraram que dos três artigos em português, dois foram publicados em 2011, e o outro em 2010, os outros quatro artigos em inglês foram publicados nos anos de 2012 e 2013, sendo que o periódico que apresentou mais artigos foi o Jounal of Sport and Health Science com dois artigos.

O quadro 2 foi construído para integração dos artigos encontrados, identificando a modalidade de dança que o artigo aborda, o tipo de estudo que é classificado, a amostra apresentada, o instrumento utilizado para realização do estudo e os resultados correspondentes. A mesma permite identificar um total de três estudos com abordagem de Dança de Salão e outros três de dança aeróbica que utiliza como instrumento o videogame, jogo: 


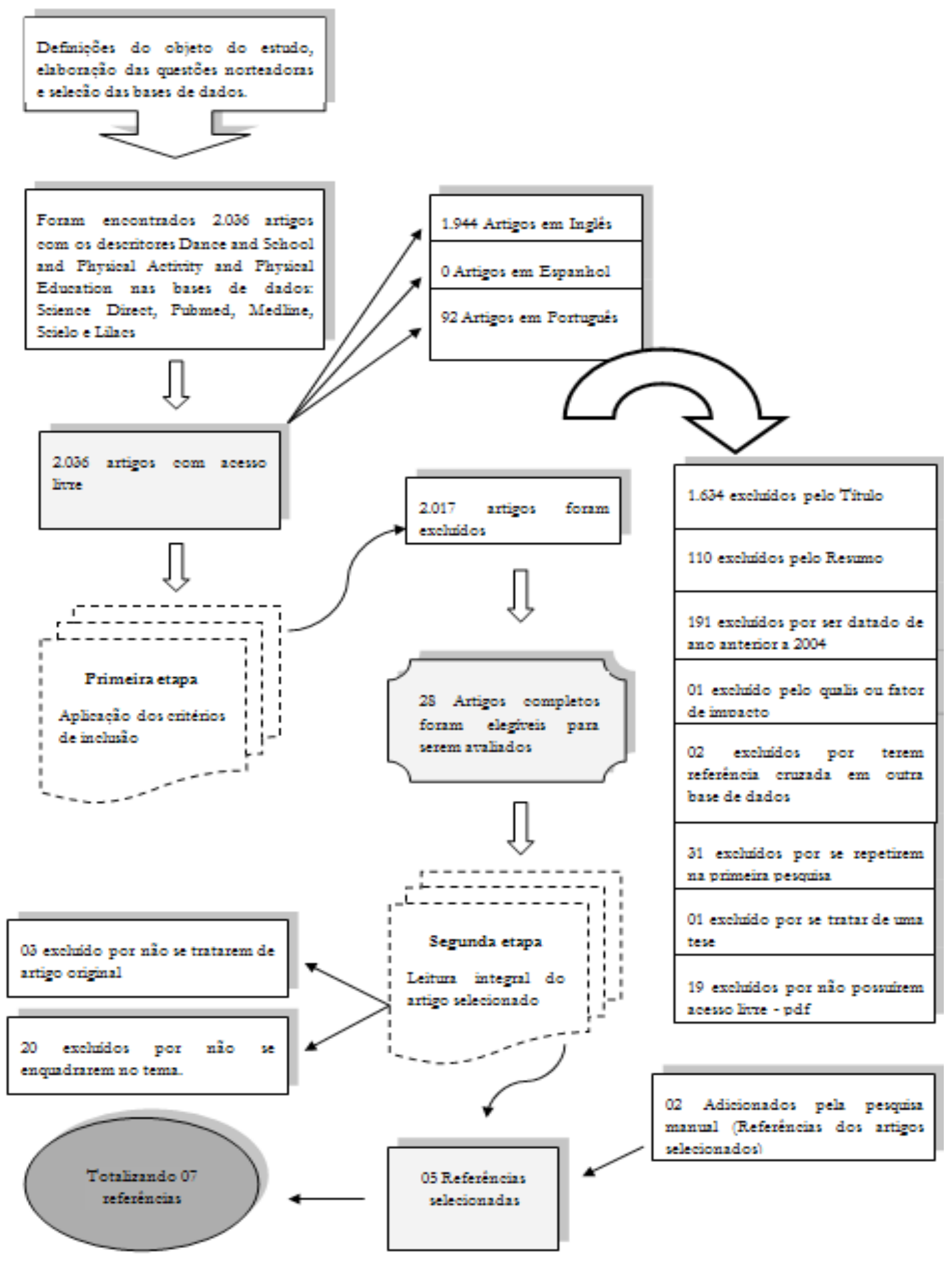

Figura 1 - Fluxograma da seleção dos estudos.

"Dance, dance, revolution" e apenas um utilizava-se da dança de rua.

Dos sete artigos selecionados, dois adotaram a metodologia de estudo transversal, outros dois foram estudos de corte prospectivo, um descritivo qualitativo, um comparativo e outro Fenomenológico Exploratório.

A amostra variou de 7 a 400 indivíduos, totalizando 922 indivíduos envolvidos. Todos os artigos envolveram, tanto estudantes do sexo masculino quanto do sexo feminino, cinco artigos realizaram a pesquisa em escolas públicas e um artigo realizou a pesquisa em escolas particulares e um não apresentou definição com relação a este aspecto. Dentre os artigos três utilizaram uma amostra de escolares do $4^{\circ}$ e $5^{\circ}$ ano do ensino fundamental, um com do $7^{\circ}$ ano do ensino fundamental, um de $3^{\circ}$ a $6^{\circ}$ ano e dois não especificaram o ano escolar. Quanto às idades, houve ao todo uma variação de 8 a 21 anos.

Os diferentes instrumentos foram classificados como diretos e indiretos, considerando questionários e/ ou formulários como indiretos e testes de laboratório, de campo, fatores antropométricos e exames clínicos como diretos. Três dos estudos apresentaram apenas instrumentos indiretos e quatro apresentaram, tanto instrumentos indiretos quanto diretos.

Os resultados mostram que a dança é bem aceita como atividade a ser utilizada nas aulas de Educação Física escolar. Três estudos que tiveram como abordagem a 
Quadro 1 - Estudos incluídos na revisão sistemática.

\begin{tabular}{|c|c|c|c|c|c|c|c|}
\hline Estudo & Ano & Título & $\begin{array}{l}\text { Idioma } \\
\text { Original }\end{array}$ & Periódico & Qualis & $\begin{array}{l}\text { Fator de } \\
\text { Impacto }\end{array}$ & Bases \\
\hline 01 & 2010 & $\begin{array}{l}\text { Dançar o adolescer: estudo fenomenológi- } \\
\text { co com um grupo de dança de rua em } \\
\text { uma escola }\end{array}$ & Português & Paidéia & B1 & 0.0732 & Lilacs \\
\hline 02 & 2011 & $\begin{array}{l}\text { Contato corporal entre adolescentes } \\
\text { através da dança de salão na escola }\end{array}$ & Português & Rev. Motriz & $\mathrm{A} 2$ & 0.0287 & Scielo \\
\hline 03 & 2011 & $\begin{array}{l}\text { Motivos da prática de dança de salão } \\
\text { nas aulas de educação física escolar }\end{array}$ & Português & $\begin{array}{l}\text { Rev. Brasileira de } \\
\text { Ed. Física e Esporte }\end{array}$ & B1 & & Scielo \\
\hline 04 & 2012 & $\begin{array}{l}\text { Impact of interactive dance games on } \\
\text { urban children's physical activity cor- } \\
\text { relates and behavior }\end{array}$ & Inglês & $\begin{array}{l}\text { Journal of Science } \\
\& \text { Fitness }\end{array}$ & A2 & & $\begin{array}{c}\text { Science } \\
\text { Direct }\end{array}$ \\
\hline 05 & 2012 & $\begin{array}{l}\text { A Ballroom Dance Classroom Program } \\
\text { Promotes Moderate to Vigorous Physical } \\
\text { Activity in Elementary School }\end{array}$ & Inglês & $\begin{array}{l}\text { American journal of } \\
\text { health promotion }\end{array}$ & & 2.37 & Pubmed \\
\hline 06 & 2013 & $\begin{array}{l}\text { Children 's physical activity levels and } \\
\text { psychological correlates in interactive } \\
\text { dance versus aerobic dance }\end{array}$ & Inglês & $\begin{array}{l}\text { Journal of Sport } \\
\text { and Health Science }\end{array}$ & - & 1.227 & $\begin{array}{l}\text { Science } \\
\text { Direct }\end{array}$ \\
\hline 07 & 2013 & $\begin{array}{l}\text { Association among children's situ- } \\
\text { ational motivation, physical activity par- } \\
\text { ticipation, and enjoyment in an active } \\
\text { dance video game }\end{array}$ & Inglês & $\begin{array}{l}\text { Journal of Sport } \\
\text { and Health Science }\end{array}$ & & 1.227 & $\begin{array}{c}\text { Science } \\
\text { Direct }\end{array}$ \\
\hline
\end{tabular}

Quadro 2 - Análise da modalidade de dança, métodos, amostragem, tipo de estudo, instrumentos e resultados.

\begin{tabular}{|c|c|c|c|c|c|c|}
\hline Estudo & Autor / Ano & Modalidade & Tipo de Dança & Amostra & Instrumento & Resultados \\
\hline 01 & $\begin{array}{l}\text { Miranda et } \\
\text { al (2010) }\end{array}$ & Dança de Rua & $\begin{array}{l}\text { Fenomenológico } \\
\text { Exploratório } \\
\text { qualitativo }\end{array}$ & $\begin{array}{l}7 \text { alunos do Ensino Mé- } \\
\text { dio; } 2 \text { do sexo feminino } \\
\text { e } 5 \text { do sexo masculino } \\
\text { de } 15 \text { à } 19 \text { anos. }\end{array}$ & $\begin{array}{l}\text { Fase exploratória de observação } \\
\text { dos alunos durante a aula de } \\
\text { dança por } 6 \text { meses; Entrevista } \\
\text { sem roteiro pré-estabelecido. }\end{array}$ & $\begin{array}{l}\text { A prática da dança de rua na } \\
\text { escola proporcionou ampliação } \\
\text { da autonomia e da autoconfiança } \\
\text { dos adolescentes. }\end{array}$ \\
\hline 02 & $\begin{array}{c}\text { Sousa et al } \\
(2011)\end{array}$ & Dança de Salão & $\begin{array}{l}\text { Descritivo } \\
\text { qualitativo }\end{array}$ & $\begin{array}{l}42 \text { alunos do } 7^{\circ} \text { ano do } \\
\text { Ensino Fundamental Es- } \\
\text { tadual } 24 \text { do sexo femi- } \\
\text { nino e } 18 \text { do masculino. } \\
\text { de } 13 \text { a } 48 \text { anos; }\end{array}$ & $\begin{array}{l}\text { Filmagem da aula de dança } \\
\text { de salão e aplicação de um } \\
\text { questionário com } 10 \text { questões. }\end{array}$ & $\begin{array}{l}60 \% \text { de evasão dos alunos } \\
\text { durante a segunda etapa da aula, } \\
\text { quando do uso da valsa; } 80 \% \text { de } \\
\text { evasão quando do uso do forró. }\end{array}$ \\
\hline 03 & $\begin{array}{l}\text { Shibukawa } \\
\text { et al (2011) }\end{array}$ & Dança de Salão & $\begin{array}{l}\text { Corte } \\
\text { transversal }\end{array}$ & $\begin{array}{l}400 \text { alunos do ensino } \\
\text { fundamental e médio } \\
\text { entre } 12 \text { a } 21 \text { anos de } \\
\text { escolas particulares } \\
\text { da cidade de } \\
\text { Florianópolis-SC. }\end{array}$ & $\begin{array}{l}\text { Questionário: motivos da } \\
\text { prática de dança de salão - } \\
\text { QMAD (SERPA,1991; SERPA } \\
\text { \& FRIAS, 1990). }\end{array}$ & $\begin{array}{l}\text { Motivações para a pratica: } \\
\text { divertimento; exercitar-se de } \\
\text { forma prazerosa; aprender novas } \\
\text { técnicas; atingir um nível de } \\
\text { dança mais elevado e estar em } \\
\text { boa condição física. }\end{array}$ \\
\hline 04 & $\begin{array}{c}\text { Gao et al } \\
(2012)\end{array}$ & $\begin{array}{l}\text { Videogame de } \\
\text { Dança }\end{array}$ & $\begin{array}{l}\text { Corte } \\
\text { transversal }\end{array}$ & $\begin{array}{l}126 \text { alunos do } 4^{\circ} \text { e } 5^{\circ} \\
\text { ano de escolas básicas, } \\
\text { de } 9 \text { a } 11 \text { anos, na } \\
\text { região de Mountain } \\
\text { West, EUA. }\end{array}$ & $\begin{array}{l}\text { Questionário auto-administrado, } \\
\text { expectativa de resultado, suporte } \\
\text { social e um pré-teste com aulas } \\
\text { de } 1 \text { semana de duração quanto } \\
\text { ao nível de atividade física. }\end{array}$ & $\begin{array}{l}\text { Grupo do videogame de dança } \\
\text { demonstraram aumento dos } \\
\text { níveis de AF; grupo de com- } \\
\text { paração ligeira diminuição na } \\
\text { participação da AF. }\end{array}$ \\
\hline 05 & $\begin{array}{c}\text { Huang S. Y. } \\
\text { (2012) }\end{array}$ & Dança de Salão & $\begin{array}{l}\text { Descritivo } \\
\text { Prospectivo }\end{array}$ & $\begin{array}{l}79 \text { alunos do } 4^{\circ} \text { e } 5^{\circ} \\
\text { anos de } 8 \text { a } 11 \text { anos de } \\
\text { duas escolas públicas } \\
\text { de Nova York, EUA. }\end{array}$ & $\begin{array}{l}\text { Sistema de observação de } \\
\text { Fitness Instruction Time } \\
\text { (SOFIT) e monitoramento direto } \\
\text { da frequência do coração. Peso } \\
\text { e altura foram medidos para } \\
\text { calcular o IMC. }\end{array}$ & $\begin{array}{l}50 \% \text { a } 67 \% \text { do tempo de aula } \\
\text { gastos em AF moderada a } \\
\text { vigorosa (AFMV). Monitoramento } \\
\text { cardíaco - } 71 \% \text { dos alunos } \geq 25 \% \\
\text { frequência cardíaca de reserva, } \\
\text { indicando AFMV, para } \geq 50 \% \text { do } \\
\text { tempo de aula. }\end{array}$ \\
\hline 06 & $\begin{array}{c}\text { Gao et al. } \\
\text { (2013) }\end{array}$ & $\begin{array}{l}\text { Videogame de } \\
\text { Dança e Dança } \\
\text { aeróbica }\end{array}$ & Comparativo & $\begin{array}{l}53 \text { alunos do } 4^{\circ} \text { ano do } \\
\text { ensino fundamental, } \\
24 \text { meninos e } 29 \\
\text { meninas de uma escola } \\
\text { pública dos EUA. }\end{array}$ & $\begin{array}{l}\text { Níveis de atividade física foram } \\
\text { medidos através de NL-1000. } \\
\text { Questionário autoadministrado. } \\
\text { Escala de satisfação por } \\
\text { Ommundsen et al. }\end{array}$ & $\begin{array}{l}\text { Crianças: maiores níveis de AFM } \\
\text { a vigorosa na dança aeróbica } \\
\text { do que no videogame de dança } \\
\text { (DDR); maior satisfação com o } \\
\text { uso do videogame. }\end{array}$ \\
\hline 07 & $\begin{array}{c}\text { Gao et al. } \\
(2013)\end{array}$ & $\begin{array}{l}\text { Videogame de } \\
\text { Dança }\end{array}$ & Prospectivo & $\begin{array}{l}215 \text { crianças do } 3^{\circ} \\
\text { a } 6^{\circ} \text { ano do ensino } \\
\text { fundamental de } 8 \text { a } \\
14 \text { anos, de escola } \\
\text { pública. }\end{array}$ & $\begin{array}{l}\text { Situação motivacional das } \\
\text { crianças para “Dance Dance } \\
\text { Revolution"; medida do } \\
\text { acelerômetro. }\end{array}$ & $\begin{array}{l}\text { Apenas motivação intrínseca } \\
\text { positivamente relacionada com } \\
\text { AFMV infantil em “Dance Dance } \\
\text { Revolution" e satisfação em } \\
\text { realizar AF. }\end{array}$ \\
\hline
\end{tabular}


dança de salão demonstram a importância do aprendizado do contato corporal com o sexo oposto, os diversos aspectos motivadores à prática da dança de salão na escola, e a intensidade significativa das atividades da aula de dança na educação física. Os três artigos que adotaram a abordagem da Dança aeróbica - videogame de dança (DDR) demonstraram que há um aumento dos níveis de atividade física com o uso do DDR, mas que a dança aeróbica tradicional ainda apresenta maiores níveis de atividade física moderada à vigorosa, sendo necessário o uso do mesmo como um complemento. Também foi descrito que a motivação intrínseca foi positivamente relacionada com a atividade física moderada à vigorosa do DDR juntamente com a satisfação. Com relação ao estudo que abordou a dança de rua foi verificado que a experiência de praticá-la no contexto da escola proporciona a ampliação da autonomia e da autoconfiança dos adolescentes.

\section{DISCUSSÃO E CONSIDERAÇÕES FINAIS}

Identificou-se a existência de poucos estudos publicados nos últimos dez anos associando-se dança ao contexto escolar. Todavia, a partir da literatura analisada foi possível observar que há uma maior incidência de estudos relacionados à dança de salão e à dança aeróbica, com o uso do videogame de dança, e um menor número de estudos relacionados à dança de rua.

Houve um maior destaque para a dança de salão. Observa-se o fato como fator positivo, visto que a mesma é uma ferramenta de grande importância para o desenvolvimento dos alunos como um todo, além de ser uma atividade que se aproxima bastante dos interesses de lazer dos adolescentes, principalmente no ensino médio ${ }^{15}$. É uma manifestação social em pares, que por si só é um indício de interação social, pois, exige o aprendizado de cuidar do próximo com respeito e possibilita o estreitamento de relações por meio da interação com o outro, fazendo uso do contato corporal ou toque $\mathrm{e}^{15-18}$. Proporcionam benefícios relacionados à saúde, podendo contribuir para o aumento dos níveis de atividade física moderada à vigorosa das crianças e adolescentes, favorecendo a mobilização de combate à obesidade desta população ${ }^{19}$.

Estudo conduzido com adolescentes e dança de salão ${ }^{18}$ destaca a questão do toque corporal, durante a prática da modalidade, encontrando $31 \%$ e $33 \%$ respectivamente para experiência relatada como agradável e desagradável. Levando em conta os fatores destacados pelos mesmos autores ${ }^{18}$, a experiência desagradável poderia ter relação com a falta de prática (ritmos pouco conhecidos: valsa, forró), timidez, medo de errar, mudanças corporais da puberdade, etc. Em desencontro a tais fatores, autores ${ }^{18,20-22}$ apontam a possibilidade de troca de experiências e companhia de amigos como incentivadores da iniciação à prática. E, mesmo com relatos de experiência desagradável, os participantes do estudo ${ }^{18}$ em sua maioria mencionam a importância da dança, reforçando os benefícios de uma boa postura, técnicas de condução e percepção de ritmo em meio às nuances musicais.

Observa-se na literatura que, embora a dança de salão seja uma atividade de boa aceitação em sua gran- de maioria, ainda há superioridade numérica do sexo feminino nas aulas de dança $a^{15,20,23,24}$. Os homens apresentam certa resistência à prática da dança, enfatizando que a prática de algumas aulas de dança na Educação Física se dá devido à obrigação ou por influência dos professores ${ }^{15,18}$. Pode-se atribuir isto à forma de criação da sociedade, no qual comportamentos rotulados como aceitáveis e não aceitáveis são reforçados durante a adolescência ${ }^{25}$. Salientam-se os populares clichês sociais como: "dança é atividade especificamente para mulheres" e "futebol é atividade especificamente de homens" 25 , provocando ainda mais preconceitos em relação às diferenças sexuais e limitando vivencias de momentos proporcionados através da dança que poderiam resultar em novas descobertas ${ }^{26}$.

A criação de videogames voltados à modalidade aparece como descoberta positiva, transformando a dança para esta nova era tecnológica, sendo bem aceita em diversos países e atraindo pessoas de todas as idades, com destaque especial às crianças e adolescentes. Ao contrário dos jogos tradicionais de videogames, que enfatizam o comportamento sedentário pelo não uso de grandes grupos musculares e gasto energético insuficiente, levando ao sobrepeso e obesidade ${ }^{19,27,28}$, o recente advento dos jogos de videogame ativos como, por exemplo: Dance Dance Revolution (DDR), Wii Fit, Esporte Kinect Wii Just Dance, e Xbox 360 Kinect Dance Central, têm a capacidade de estimular as crianças a adotarem um estilo de vida mais ativo e saudável de forma motivadora e prazerosa ${ }^{19,27,28}$, como mostram os estudos incluídos nesta revisão. Estes são uma possibilidade de uso na Educação Física Escolar, pois a interação da atividade física comum com o videogame de dança é amplamente aceita pelos alunos e favorece o aumento das atividades físicas diárias moderadas a vigorosas, melhorando os aspectos da saúde dos jovens e ainda motivando os mesmos para a prática fora dos videogames.

Outro estilo de dança preferido pelos escolares foi a dança de rua, e nesta modalidade, a diferença entre os sexos não fica tão evidente. Os adolescentes em especial, demonstram uma forte identificação com esta modalidade, por ser parte de uma cultura que exalta as diferenças e injustiças sociais ${ }^{29}$. A dança de rua é apenas uma parte da cultura hip-hop, que pode ser considerada um sistema que orienta os jovens no autoconhecimento e no conhecimento da sociedade que o cerca, promovendo intervenções práticas de maneira imediata $^{29}$. As intervenções na escola se dão por meio das acrobacias do breaking dance, locking, popping, freestyle, boogaloo e brooklyn rock que se tratam de estilos diferentes de se dançar. A estrutura da aula normalmente se dá com a reprodução de coreografias fazendo uso de movimentos, desde fluidos a espacatos, fortes, sincronizados, buscando ora uma estética simétrica ora assimétrica ${ }^{30}$. As manifestações do hip-hop são importantes ferramentas de expressão, com a qual é possível constituir uma identidade, aumentar a autoestima, criar o sentimento de pertencer a algo, interpretar a sua própria realidade a fim de aceitar para mudar ${ }^{29,31}$. Com isso, mostra-se como uma grande oportunidade, a implantação da dança de rua nas escolas brasileiras, pois segundo Molina et $\mathrm{al}^{25}$ e Outeiral ${ }^{32}$ esta tem o privilégio de promover o crescimento de crianças 
e adolescentes por meio de diferentes práticas culturais e esportivas, construir com a orientação dos professores um "eu" mais consciente, com relação ao seu papel na sociedade ${ }^{25,32}$.

Ao analisar os estudos que compõe esta revisão identificou-se uma lacuna existente em estudos que relacionam a dança à Educação Física escolar, pois, apenas três modalidades de dança foram associadas à Educação Física, sendo que muitas outras podem ser exploradas no contexto escolar, como por exemplo: as danças populares, dança criativa, dança contemporânea, entre outras. Portanto, cabe a proposta de novos estudos de campo com intervenção relacionando à dança na escola, identificando as diferenças entre sexos, idades, região e tipo de escola (pública e privada), mostrando a importância de se trabalhar e desenvolver a dança no ambiente escolar. Concluiu-se com este estudo, que a dança utilizada como ferramenta auxiliadora na Educação Física escolar, proporciona benefícios ao estado biopsicossocial do aluno, trazendo conhecimentos importantes para a vida, devendo ser desenvolvida nas séries iniciais, motivando o aluno para a sua prática, necessitando ser mais explorada no contexto da escola.

\section{REFERÊNCIAS}

1. Volp CM. A Dança de Salão como um dos conteúdos de dança na escola. Motriz, Rio Claro, 2010; 17(4): 618-629.

2. Magalhães MC. A dança e sua característica sagrada, "Existência e Arte"- Revista Eletrônica do Grupo PET - Ciências Humanas, Estética e Artes da Universidade Federal de São João Del-Rei - Ano I - Número I - janeiro a dezembro de 2005.

3. Oliveira VM. O que é educação física. São Paulo: Brasiliense; 2001.

4. Gariba CMS. Dança escolar: uma possibilidade na Educação Física. Movimento, Porto Alegre, 2007; 13(2): 155-171.

5. Barreto D. Dança: Ensino, sentidos e possibilidades na escola. São Paulo: Autores Associados; 2004.

6. Sborquia SP, Gallardo J.S.P. A dança no contexto da educação física. ljuí: UNIJUí; 2006.

7. Saraiva MC, Fiamoncini L, Abrão E, Krischke AA. Dança e seus elementos constituintes: uma experiência contemporânea. In: SILVA, Ana Márcia; DAMIANI, lara Regina (org.). Práticas corporais: Experiências da Educação Física para a outra formação humana. Florianópolis: Nauemblu Ciência \& Arte; 2005.

8. Prado APA, Lima KA, Rezende LQ. A criança e sua motricidade da dança. XXV Congresso Nacional de Educação - CONADE - CAJ/UFG; 2009.

9. Silva WF, Alves DS, Ribeiro GFF. A Dança nas escolas da rede estadual de ensino fundamental na cidade de Porteirinha/ MG: Análise da sua aplicabilidade e metodologias. Educação Física em Revista, 4(02), 2010.

10. Silveira GCF, Pinto JF. Educação Física na perspectiva da cultura corporal: Uma proposta pedagógica; IN: Revista Brasileira de Ciências do Esporte, 2001; 22(3): 137-150.

11. BRASIL. Ministério da Educação. Secretaria de Educação Básica. Parâmetros curriculares nacionais: educação física. Brasília: MEC/SEB; 1997.

12. BRASIL. Ministério da Educação. Secretaria de Educação Básica. Parâmetros curriculares nacionais: educação física.
Brasília: MEC/SEB; 1998

13. BRASIL. Parâmetros curriculares nacionais: ensino médio. Brasília: MEC/SEB; 1999.

14. Resende HG. Subsídios para uma pedagogia da educação física escolar numa perspectiva da cultura corporal. In: Cultura, atividade corporal e esporte. VOTRE S. J. (org) et al. Rio de Janeiro: Editora Central da Universidade Gama Filho, 1995.

15. Shibukawa RM, Guimarães ACA, Simas J. Motivos da prática de dança de salão nas aulas de educação física escolar. Rev. bras. Educ. Fís. Esporte, São Paulo, 2011; 25(1): 19-26.

16. Freire IM. Dança-educação: O corpo e o movimento no espaço do conhecimento. Cadernos Cedes, Campinas, 2001; 21(53): 31-55.

17. Perna MA. Samba de gafieira: a história da dança de salão brasileira. Rio de Janeiro: Edição do Autor; 2005.

18. Sousa NCP, Caramaschi S. Contato corporal entre adolescentes através da dança de salão na escola. Motriz, Rio Claro, 2011; 17(4): 618-629.

19. Gao Z, Huang C, Liu T, Xiong W. Impact of interactive dance games on urban children's physical activity correlates and behavior. Journal of Exercise Science \& Fitness, 2012; 10(2): 107-112.

20. D'aquino R, Guimarães ACA, Simas JPN. Dança de salão: motivos dos indivíduos que procuram esta atividade. Lecturas, Educación Física y Deportes: Revista Digital, Buenos Aires, 2005; 10(88).

21. Nieminen P. Motives for dancing among finnish folk dancers, competitive ballroom dancers, ballet dancers and modern dancers. Physical Education \& Sport Pedagogy, London, 1998; 3(1): 22-34.

22. Scarpato MT. Dança educativa: Um fato em escolas de São Paulo. Cadernos Cedes, 2001; 21(53): 57-68.

23. Goobbo DE. A dança de salão como qualidade de vida para a terceira idade. Revista Eletrônica de Educação Física UniAndrade, Curitiba, a.1, v.2; 2005.

24. Volp CM, Deutsch S, Schwartz GM. Por que dançar? Um estudo comparativo. Motriz, Rio Claro, 1995; 1(1): 52-58.

25. Molina RMK, Silva LO, Silveira FV. Celebração e transgressão: A representação do esporte na adolescência. Revista Brasileira de Educação Física e Esporte, 2004; 18: 125-36.

26. Saraiva KMC et al. Improvisação \& Dança. Florianópolis: Ed. UFSC; 1998.

27. Gao Z, Podlog P, Huang C. Associations among children's situational motivation, physical activity participation, and enjoyment in an active dance video game. Journal of Sport and Health Science, 2013; 2(2): 122-128.

28. Gao Z, Zhang T, Stodden D. Children's physical activity levels and psychological correlates in interactive dance versus aerobic dance. Journal of Sport and Health Science, 2013; 2(3): 146-151.

29. Scandiucci G. Cultura hip hop: um lugar psíquico para a juventude negro-descendente das periferias de São Paulo. Imaginario, São Paulo; 2006.

30. Ejara F. A História da Dança de Rua Clássica, $3^{\circ}$ Encontro de Hip Hop do Colégio Fênix, 2004.

31. Carril LFB. Quilombo, favela e periferia: a longa busca da cidadania. 2003. [Tese] (Doutorado em Geografia Humana). Faculdade de Filosofia, Letras e Ciências Humanas, Universidade de São Paulo, São Paulo; 2003.

32. Outeiral JO. Adolescer: Estudos sobre adolescência. Porto Alegre: Artes Médicas; 1994. 